\title{
Hemostasis Imbalance in Experimental Hypertension
}

\author{
Delphine Corseaux, ${ }^{1}$ Véronique Ollivier, ${ }^{1}$ Vincent Fontaine, ${ }^{3}$ Marie-Geneviève Huisse, ${ }^{2}$ \\ Monique Philippe, ${ }^{3}$ Liliane Louedec, ${ }^{3}$ Roger Vranckx, ${ }^{3}$ Catherine Ravanat, ${ }^{4}$ François Lanza, \\ Edouardo Angles-Cano, ${ }^{3}$ Marie-Claude Guillin, ${ }^{2}$ and Jean-Baptiste Michel $^{3}$
}

\author{
${ }^{1}$ INSERM U479, Faculté Xavier Bichat, Paris, France \\ ${ }^{2}$ INSERM E9907, Faculté Xavier Bichat, Paris, France \\ ${ }^{3}$ INSERM U460, Faculté Xavier Bichat, Paris, France \\ ${ }^{4}$ INSERM U311, Etablissement Français du Sang, Strasbourg, France
}

Accepted March 18, 2002

\begin{abstract}
Background: The rat model of chronic intoxication by $\mathrm{N}^{\mathrm{G}}$-nitro-L-arginine methyl ester (L-NAME) induces severe systemic arterial hypertension and progressive ischemic lesions in the central nervous system and kidneys. We investigated the possible molecular basis of these thrombotic events.

Methods and Results: Administration of L-NAME increased plasma markers of thrombin generation, thrombin-antithrombin complexes, and soluble glycoprotein V, measured by specific ELISA. Thrombin generation in vivo was associated with ex vivo platelet desensitization to adenosine $5^{\prime}$-diphosphate and collageninduced aggregation. In the aortic layers and renal arterioles, tissue factor mRNA (semi-quantitative RT-PCR) and activity (coagulation assay) were increased. In contrast, tissue factor activity was not modified in glomeruli. In parallel, an impairment of the fibrinolytic system was
\end{abstract}

demonstrated by an increase in plasma levels and arterial secretion of plasminogen activator inhibitor-1. In the arterial wall, plasminogen activator inhibtor-1 mRNA was significantly increased. Moreover, antifibrinolytic activity, studied by fibrin reverse zymography, was increased whereas all tissue-plasminogen activator activity secreted by the hypertensive arterial wall was detected as complexes with its specific inhibitor. In animals treated with the angiotensin-converting enzyme (ACE) inhibitor Zofenil, all of these parameters remained at control levels.

Conclusions: These results indicate that chronic blockade of nitric oxide production in rats results in enhancement of blood markers of thrombin generation associated with tissue factor induction and impairment of fibrinolysis in the vascular wall, which may contribute to the thrombotic complications associated with hypertension.

\section{Introduction}

Hypertension is an important risk factor for cardiovascular morbidity and mortality (1). Myocardial infarction, nephroangiosclerosis, and stroke, which are complications of hypertension, predominantly occur due to thrombosis of arterioles leading to ischemia and infarcts (2). Thrombotic risk associated with hypertension mainly targets the central nervous system, heart, and kidneys, leading to functional impairment and fibrosis of these tissues (3). It has been recently shown that an increase in intima/media thickness of the carotid artery is correlated with the risk of brain infarction (4), providing clinical evidence of a link between arterial wall morphologic remodeling and thrombotic risk in the central nervous system. Nevertheless, the molecular basis of this relationship has not yet been extensively investigated.

D.C. and V.O. contributed equally to this work. Correspondence and reprint requests should be addressed to: Véronique Ollivier, INSERM U479, Faculté Xavier Bichat, BP 416, 75870 Paris CEDEX 18, France. Phone: 33144856213 . fax: 331448562 07; e-mail: ollivier@bichat.inserm.fr.
Chronic blockade of vascular nitric oxide (NO) production by $\mathrm{N}^{\mathrm{G}}$-nitro-L-arginine methyl ester (L-NAME) induces the development of severe hypertension in rats associated with an important decrease in arterial wall cyclic GMP content (5), renal damage (6), and ischemic stroke (7), in which potentiation between extracellular vasoconstrictor factors and intracellular signaling plays a predominant pathophysiologic role (8). In addition to the induction of arterial wall morphologic remodeling, L-NAME-induced hypertension increases the expression of various genes such as anti-proteases: tissue inhibitor of metalloproteinases (TIMP) (9) and plasminogen activator inhibitor-1 (PAI-1) (10) within the arterial wall. Expression of proinflammatory genes (11) is induced in the L-NAME model and mediated, at least in part, by oxidative stress and nuclear factor- $\kappa \mathrm{B}(\mathrm{NF}-\kappa \mathrm{B})$ activation $(9,12)$, providing evidence of the molecular plasticity of vascular cells in response to hypertension. This modulation of arterial wall phenotype leads to a reduced survival expectancy in this model, which is completely reversed by inhibition of the renin-angiotensin system (13). 
In view of the overexpression of secreted antiproteases in hypertension (14) and because the induction of the expression of tissue factor (TF), the main initiator of thrombogenesis in the vascular wall (15), is NF$\kappa \mathrm{B}$-dependent (16), we hypothesized that the arterial wall may contribute to the impairment of fibrinolysis and hypercoagulability involved in the thrombotic risk observed in hypertensive rats. To examine this point, we administered L-NAME to rats, providing a model of severe hypertension and endothelial dysfunction leading to arteriolar thrombosis in different target organs. We explored thrombin formation in the blood, and TF expression and fibrinolysis in the arterial wall. Finally, because inhibition of the renin-angiotensin system is able to prevent functional and structural arterial wall remodeling in the L-NAME model, we tested the ability of an angiotensin converting enzyme inhibitor (ACEI) Zofenil to prevent the genesis of thrombin and the impairment of the fibrinolytic cascades.

\section{Methods}

Experimental Design

Male Wistar rats (IFFA CREDO, Lyon, France), $150 \mathrm{~g}$ body weight, were used. Rats were randomly divided into three groups: controls, $n=30$, L-NAME, $50 \mathrm{mg} / \mathrm{kg} / \mathrm{d}$ in the drinking water, $n=40$ (SigmaAldrich, Saint Quentin Fallavier, France), and LNAME (as above) plus Zofenopril (L-NAME + ACEI; $15 \mathrm{mg} / \mathrm{kg} / \mathrm{d}, n=27)$. Zofenopril was a generous gift of Menarini (Firenze, Italy) and was given daily in the diet.

Systolic blood pressure (BP), measured by the tail-cuff method, and body weights were recorded once a week. After 8 weeks, blood was sampled, rats were sacrificed under pentobarbital anesthesia, and hearts removed and weighed. Kidneys and aortas were removed and dissected clean. Blood was centrifuged and plasma was frozen $\left(-80^{\circ} \mathrm{C}\right)$ for further analysis. Tissue and plasma assays were performed in 8-12 animals per group.

The experimental design complied with the Principles of Laboratory Animal Care formulated by the National Society for Medical Research and the Guide for the Care and Use of Laboratory Animals (NIH publication No. 86-23, revised 1989; authorization $\mathrm{N}^{\circ}$ 00577, Paris France).

\section{Plasma Assays}

The fibrinogen level was measured according to the Clauss technique using an STA coagulation analyzer (Diagnostica Stago, Asnières, France). PAI-1 antigen was measured using the Lymutest rat-PAI- 1 antigen assay (Hyphen Biomed, Andresy, France). Thrombinantithrombin complexes (TAT) and soluble glycoprotein V (sGPV) were measured using, respectively, a commercially available ELISA (Enzygnost TAT micro, Dade Behring, Paris-La Défense, France) and an ELISA specific for rat SGPV developed by C.R. as described previously (17).

\section{Platelet Count and Aggregation}

Platelet counts were performed on whole blood collected on EDTA using a Bayer Hl counter. The measurement of platelet aggregation was performed in citrated platelet-rich plasma by the turbidimetric method using a 4-channel aggregometer (Coulter, Villepinte, France). Platelet aggregation was determined as the maximal change of light transmission after the addition of adenosine 5'-diphosphate (ADP) ( 3 and $6 \mu \mathrm{mol} / \mathrm{L}$, Biodata, USA) or collagen (30 $\mu \mathrm{g} / \mathrm{ml}$, Horm Nycomed, München, Germany).

\section{Isolation of Glomeruli}

Glomeruli were isolated from the kidneys as described previously (18). Aliquots of freshly isolated glomeruli were used immediately or were sonicated before performing clotting assays.

\section{Isolation of Renal Afferent Arterioles}

Renal afferent arterioles were isolated using iron oxide perfusion according to Chatziantoniou et al. (19). Arterioles, recovered with a magnetic bar, were sonicated and iron oxide was removed before performing clotting assays.

\section{Arterial Wall Dissection}

Whole aortas, including the three layers, were removed and directly frozen in liquid nitrogen for mRNA extraction. In some rats, media were separated from adventitia (20). The different tissue layers were homogenized in $\mathrm{N}$-octyl- $\beta$-D glucopyranoside using a polytron homogenizer (Bioblock, Illkirch, France) and homogenates were frozen $\left(-80^{\circ} \mathrm{C}\right)$. TF procoagulant activity was measured in the supernatants of these homogenates after thawing.

Both whole aorta and the media layer were cut into rings and incubated for $24 \mathrm{hr}$ in $500 \mu \mathrm{l}$ of DMEM at $37^{\circ} \mathrm{C}$. The supernatant was then collected and used for measurement of PAI-1 secretion and evaluation of fibrinolytic and antifibrinolytic activity.

\section{TF Assay}

The procoagulant activity (PCA) of TF was measured in isolated glomeruli and renal arterioles as well as in the media and adventitial layers of aortas using the recalcification time of a citrated normal rat platelet-poor plasma as described previously (18). Clotting times were compared to those obtained with a standard rat brain thromboplastin preparation (21). PCA was characterized as TF by using human Phe-Phe-Arg chloromethylketone-inactivated factor VIIa (FVIIai, generously given by Novo Nordisk, Gentofte, Denmark).

Detection of Plasminogen Activators and PAI-1 by Fibrin Zymography

Zymography analysis of plasminogen activators and PAI- 1 was performed as described (22). Fibrin zymograms were allowed to develop at $37^{\circ} \mathrm{C}$ for 
4-24 hr and were then photographed at regular intervals using dark-ground illumination. Fibrinolytic activity was quantified by densitometry using $\mathrm{NIH}$ Image 1.60 software. The experiment was repeated twice.

Comparative Analysis of TF, Tissue Factor Pathway Inhibitor, PAI-1, and Tissue Plasminogen Activator mRNA Expression by RT-PCR

Total RNA was extracted from aortic and glomerular samples using the TRIzol Reagent (Life Technologies, Cergy Pontoise, France). RT-PCR was performed as previously described (9). TF, tissue factor pathway inhibitor (TFPI), PAI-1, and tissue plasminogen activator (t-PA) mRNA expressions were normalized to that of the "housekeeping" gene glyceraldehyde-3-phosphate dehydrogenase (G3PDH) mRNA (Table 1).

\section{Statistical Analysis}

Results are expressed as mean \pm SEM. Data were analyzed using a nonparametric test (Kruskal-Wallis) followed by the Mann-Whitney U test to determine the significance of differences between groups. Linear regression curves and correlation coefficients were obtained by the least-squares method.

\section{Results}

Body Weight, Heart Weight, and Systolic BP

During the 8 weeks of treatment, no significant differences in body weights were observed between the three groups. In the L-NAME group, systolic BP was significantly higher compared to the control and L-NAME + ACEI groups. In the L-NAME + ACEI group, systolic BP was similar to the control group. In the L-NAME group, the heart weight and consequently the heart to body weight ratio were significantly higher than in control and L-NAME + ACEI groups (Table 2 ).

\section{Plasma Markers of Thrombin Generation}

In the L-NAME group, the fibrinogen level was increased compared to those of the control and L-NAME + ACEI groups $(5.1 \pm 0.5$ versus $4.4 \pm 0.2$ and versus $3.5 \pm 0.1 \mathrm{~g} / \mathrm{L}, p<0.001)$. TAT and sGPV plasma levels were also increased (Figs. $1 \mathrm{~A}$ and $\mathrm{IB}$ ). In the L-NAME + ACEI group, the sGPV level was similar to that of the control group, and the moderate increase observed in the TAT level was not significant (Figs. IA and 1B). Both circulating markers of thrombin generation were highly correlated $(r=0.87, p<0.0001$, Fig. 1C). Specifically, in the L-NAME group, systolic BP and TAT were significantly correlated $(r=0.72, p<0.01$, Fig. ID).

\section{Platelet Count and Aggregation}

No difference in platelet count was observed between the three groups (Fig. 2A). In the L-NAME group, ex vivo platelet aggregation in response to ADP ( 3 or $6 \mu \mathrm{mol} / \mathrm{L})$ or collagen $(30 \mu \mathrm{g} / \mathrm{ml})$ was significantly decreased compared to controls (Fig. 2B) suggesting a desensitization of platelets in the L-NAME group. By contrast, in the L-NAME + ACEI group, ADP and collagen-induced platelet aggregation were similar to control values (Fig. 2B). Systolic BP was negatively correlated with platelet aggregation induced by $6 \mu \mathrm{mol} / \mathrm{L}$ ADP $(r=-0.58, p=0.006$, Fig. $2 \mathrm{C})$ or $30 \mu \mathrm{g} / \mathrm{ml}$ collagen $(r=-0.75, p=0.0007$, Fig. 2D).

Table 1. Primer sequences derived from rat cDNAs used in the RT-PCR assays

\begin{tabular}{|c|c|c|c|}
\hline Primers & Sequences & $\begin{array}{l}\text { Amplification } \\
\text { size }\end{array}$ & $\begin{array}{l}\text { Annealing } \\
\text { temperature/ } \\
\text { cycles }(n)\end{array}$ \\
\hline $\mathrm{TF}$ & & & \\
\hline $\begin{array}{l}\text { Upstream } 107 \\
\text { Downstream } 230\end{array}$ & $\begin{array}{l}\text { 5'-CCACCTTTCTCGGCTTCCTTC-3' } \\
\text { 5'-GGTTTCGGTTGCCACTCCAAG-3' }\end{array}$ & $126 \mathrm{bp}$ & $61^{\circ} \mathrm{C} / 29$ \\
\hline $\begin{array}{l}\text { TFPI } \\
\text { Upstream } 272 \\
\text { Downstream } 600\end{array}$ & $\begin{array}{l}\text { 5'-TGCAAAGCAATGATACGGAG-3' } \\
\text { 5'-CTGCACTCCTCCAAGGTCTC-3' }\end{array}$ & $329 \mathrm{bp}$ & $60^{\circ} \mathrm{C} / 32$ \\
\hline $\begin{array}{l}\text { t-PA } \\
\text { Upstream } 704 \\
\text { Downstream } 1088\end{array}$ & $\begin{array}{l}\text { 5'-CACAGCTTTACCACATCCAA-3' } \\
\text { 5'-CAGATAGCACCCAGCAGGAA-3' }\end{array}$ & $385 \mathrm{bp}$ & $60^{\circ} \mathrm{C} / 28$ \\
\hline $\begin{array}{l}\text { PAI-1 } \\
\text { Upstream } 851 \\
\text { Downstream } 1170\end{array}$ & $\begin{array}{l}\text { 5'-GACATCCTGGAACTGCCCTA-3' } \\
\text { 5'-ACCTCGATCTTGACCTTTTG-3' }\end{array}$ & $320 \mathrm{bp}$ & $60^{\circ} \mathrm{C} / 28$ \\
\hline $\begin{array}{l}\text { GAPDH } \\
\text { Upstream } 34 \\
\text { Downstream } 333\end{array}$ & $\begin{array}{c}\text { 5'-GTGAAGGTCGGTGTCAACG-3' } \\
\text { 5'-GGTGAAGACGCCAGTAGACTC-3' }\end{array}$ & $300 \mathrm{bp}$ & $55^{\circ} \mathrm{C} / 27$ \\
\hline
\end{tabular}


Table 2. General parameters of treated and untreated rats

\begin{tabular}{lccc}
\hline & $\begin{array}{c}\text { Controls } \\
(n=30)\end{array}$ & $\begin{array}{c}\text { L-NAME } \\
(n=40)\end{array}$ & $\begin{array}{c}\text { L-NAME + ACEI } \\
(n=27)\end{array}$ \\
\hline Body weight $(\mathrm{g})$ & $451 \pm 11$ & $440 \pm 11$ & $468 \pm 6$ \\
Heart weight $(\mathrm{mg})$ & $1300 \pm 20$ & $1450 \pm 50^{*}$ & $1190 \pm 40^{\$ *}$ \\
Heart weight/body weight $(\mathrm{mg} / \mathrm{g})$ & $2.88 \pm 0.05$ & $3.57 \pm 0.12^{* *}$ & $2.65 \pm 0.13^{\$}$ \\
Systolic blood pressure $(\mathrm{mm} \mathrm{Hg})$ & $149 \pm 3$ & $216 \pm 5^{* *}$ & $146 \pm 3^{\$ \$}$ \\
\end{tabular}

Values are mean \pm SEM.

${ }^{*} p<.05$ versus controls.

${ }^{* *} p<.005$ versus controls.

$\$ p<.05$ versus L-NAME.

${ }^{\$ \$} p<.005$ versus L-NAME.

\section{TF and TFPI in the Aorta}

The amount of TF mRNA was significantly increased in the whole aorta of the L-NAME group compared to the control and L-NAME + ACEI groups ( $p<0.005$, Fig. 3A); no significant variation in TFPI mRNA was observed with L-NAME treatment. In the L-NAME group, increased expression of TF was associated with a significant increase in TF activity in both the media (Fig. 3B) and the adventitia (Fig. 3C), compared to the control and L-NAME + ACEI groups. PCA was identified as TF, because preincubation of 100 nmol/L FVIIai for $10 \mathrm{~min}$ with the samples inhibited more than $80 \%$ of the measured PCA. A strong correlation was observed between systolic BP and arterial TF activity ( $r=0.73, p<0.0001$, Fig. 3D).
TF and TFPI in Glomeruli and Renal Arterioles

No significant variation of TF mRNA was observed in the glomeruli with L-NAME or L-NAME + ACEI treatment compared to the control group (Fig. 4A). Similarly, TF activity remained unmodified whether the glomeruli were intact or disrupted (Fig. 4B). By contrast, TFPI mRNA was significantly decreased in the glomeruli of L-NAME- or L-NAME + ACEI-treated rats (Fig. 4A). TF activity was significantly increased in renal arterioles in the L-NAME group compared to the control group or L-NAME + ACEI group (Fig. 4C). A strong correlation was observed between systolic BP and TF activity in the renal arterioles $(r=0.76, p<0.0001$, Fig. 4D).

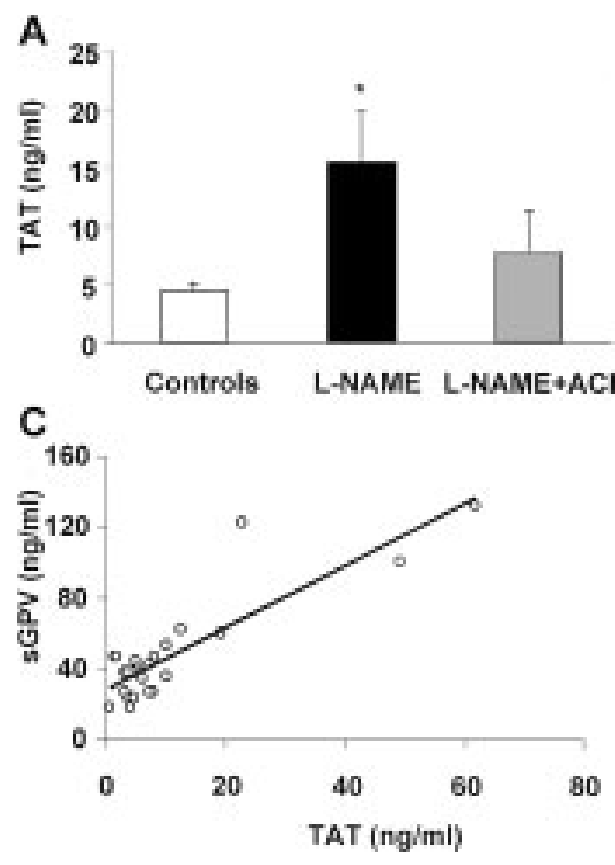

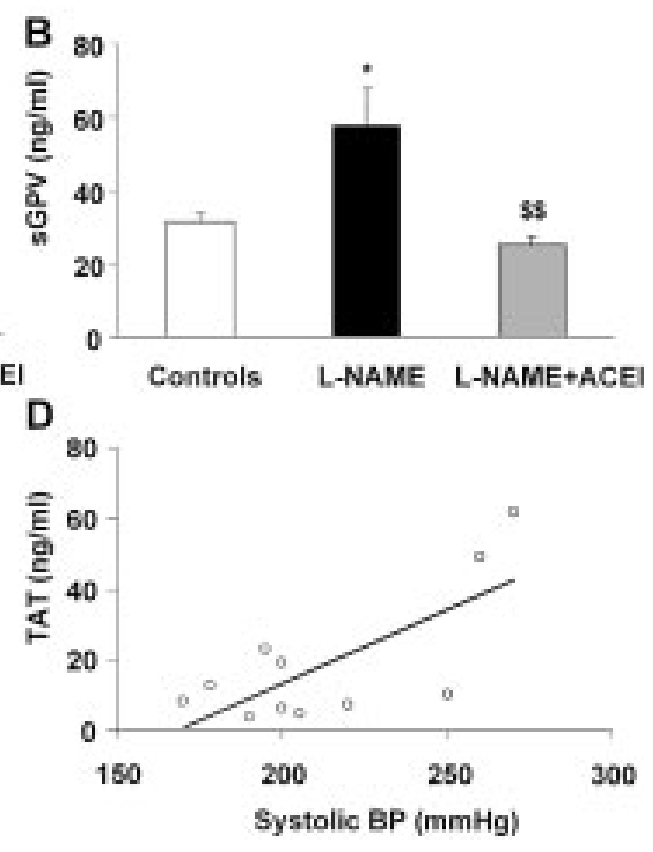

Fig. 1. Plasma markers of thrombin production. Plasma TAT (A) and sGPV (B) levels in the three groups of rats. These two parameters of thrombin activation were correlated $(\mathbf{C} ; r=0.87$, $p<0.0001)$. Plasma concentration of TAT was strongly correlated with the systolic BP in the L-NAME hypertensive rats $(\mathbf{D} ; r=0.72$, $p<0.01)$. Values are means \pm SEM. ${ }^{*} p<0.05$ versus controls. ${ }^{\$} \$ p<$ 0.005 versus L-NAME. 
A

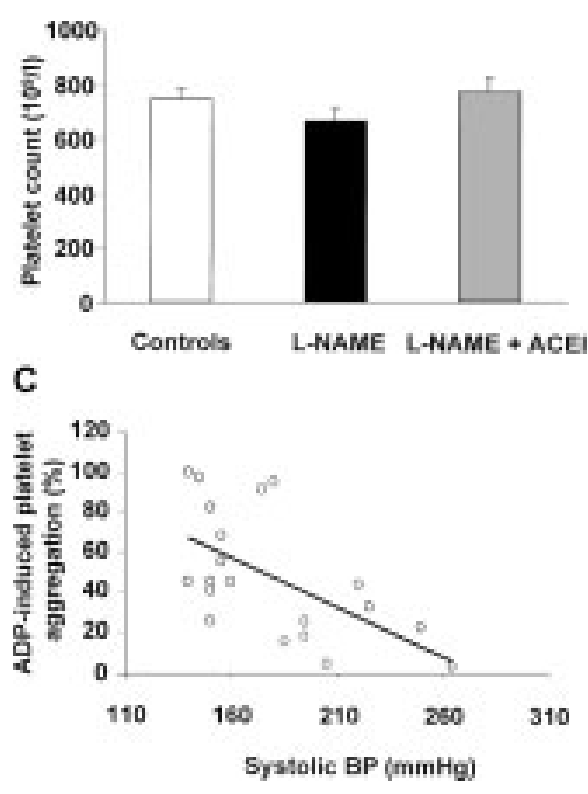

B
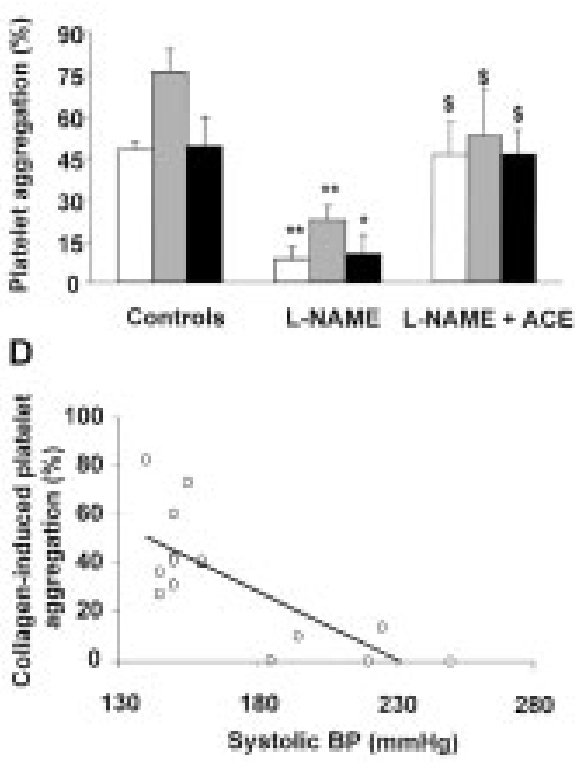

Fig. 2. Platelet count and activation. Platelet count (A). Intensity of platelet aggregation (B) induced by $3 \mu \mathrm{mol} / \mathrm{L}$ ADP (open bar), $6 \mu \mathrm{mol} / \mathrm{L}$ ADP (grey bar) or $30 \mu \mathrm{g} / \mathrm{ml}$ collagen (filled bar). A significant decrease in platelet response to ADP or collagen was observed in the L-NAME group. Platelet aggregation induced by $6 \mu \mathrm{mol} / \mathrm{L}$ ADP (C) or $30 \mu \mathrm{g} / \mathrm{ml}$ collagen (D) was negatively correlated with systolic BP $(r=-0.58, p=0.006$ and $r=-0.75, p=0.0007$ respectively, all animals). Values are means \pm SEM. ${ }^{*} p<0.05,{ }^{* *} p<0.005$ versus controls. $\$_{p}<0.05$ versus L-NAME.

\section{Fibrinolysis Impairment}

In the L-NAME group, a non-significant increase in plasma PAI- 1 antigen (ELISA) was observed compared to the control and the L-NAME + ACEI groups (Fig. 5A). In the L-NAME + ACEI group, PAI-1 antigen level was similar to that of the control group (Fig. 5A).
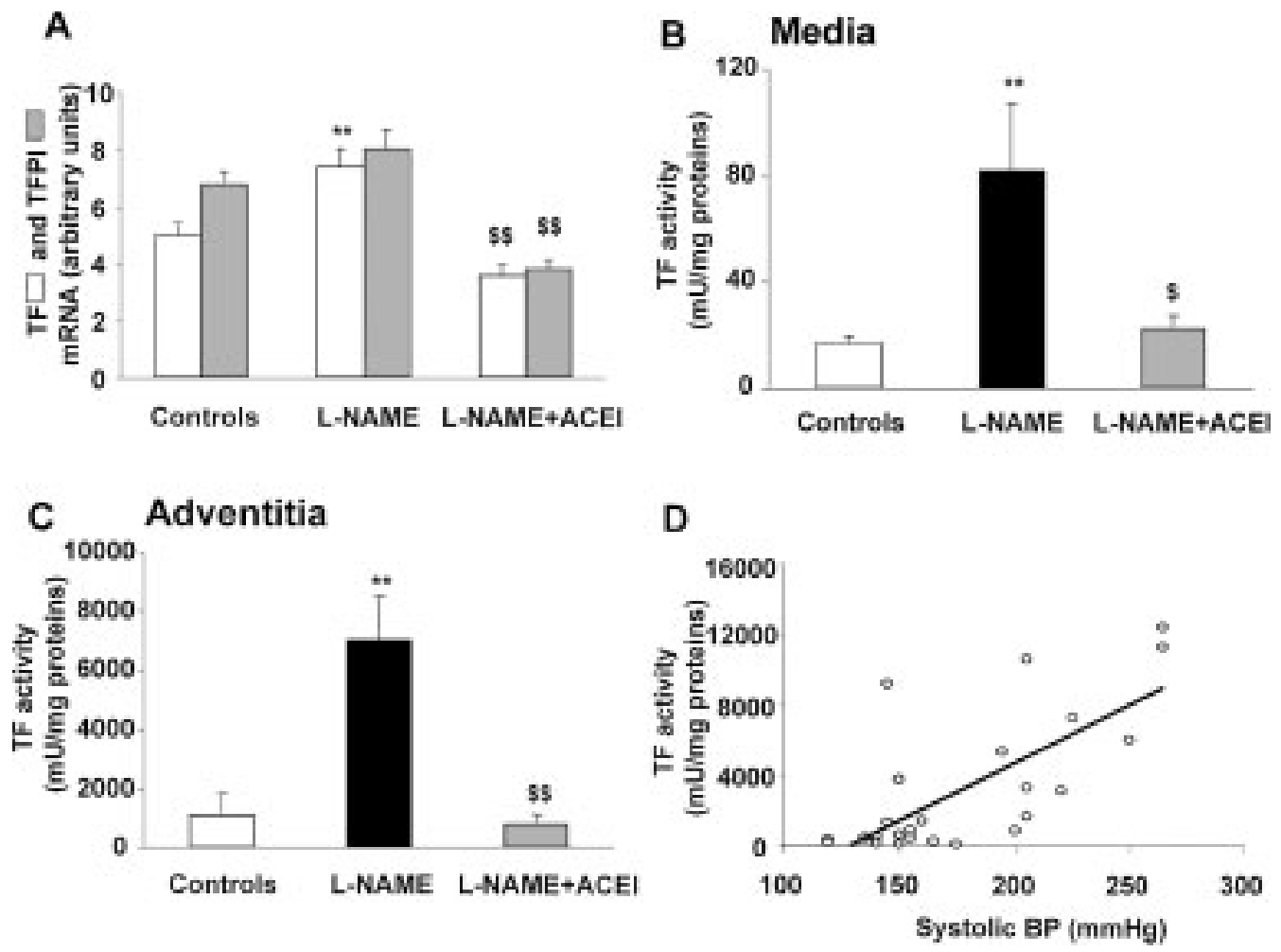

Fig. 3. Aortic TF and TFPI expression. (A) TF (open bar) and TFPI (grey bar) mRNA expression in the arterial wall. A significant increase in TF mRNA was observed; TFPI mRNA expression was not modified by L-NAME treatment. Evolution of TF activity in homogenates of media (B) and adventitia (C). A significant increase in TF activity was observed in the aortic layers in the L-NAME group. TF activity of the adventitia was strongly correlated with systolic BP (D; $r=0.73, p<0.0001$, all animals). Values are means \pm SEM. ${ }^{* *} p<0.005$ versus the control group. ${ }^{\$} p<0.05,{ }^{\$ \$} p<0.005$ versus L-NAME. 


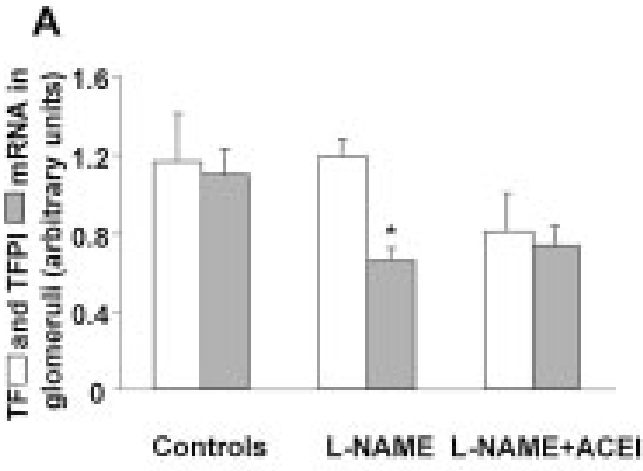

\section{B Glomeruli}
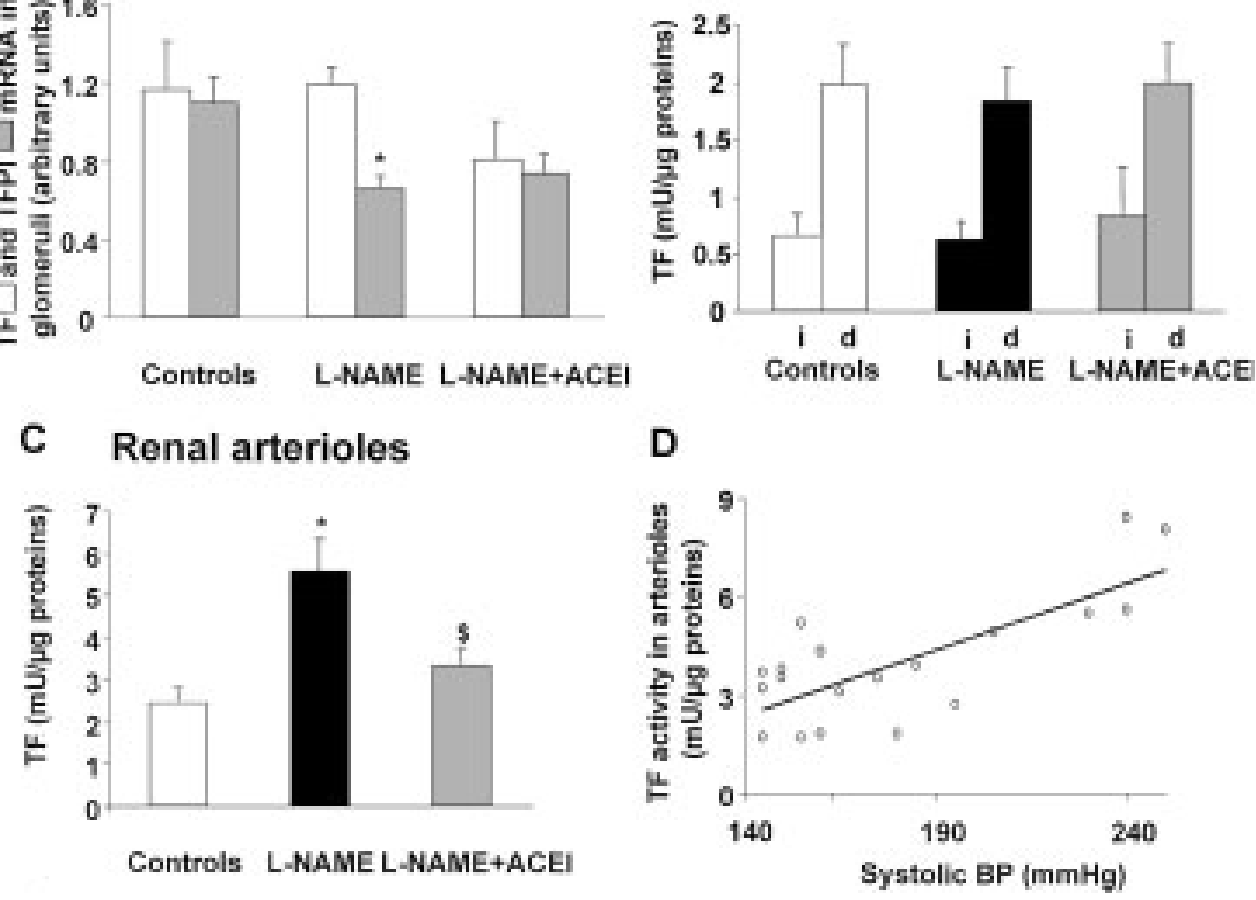

Fig. 4. Renal TF and TFPI expression. (A) mRNA expression. TF mRNA expression (open bar) was not increased in the glomeruli of L-NAME rats. Nevertheless, TFPI mRNA expression (gray bar) was significantly decreased in this group. Evolution of TF activity in intact (i) or disrupted (d) glomeruli (B) and in disrupted arterioles (C). A significant increase in TF activity was observed in arterioles of the L-NAME rats. By contrast, no variation of TF activity was observed in glomeruli. TF activity of arterioles was strongly correlated with systolic BP (D; $r=0.76, p<$ 0.0001 , all animals). Values are means \pm SEM. ${ }^{*} p<0.05$ versus controls. ${ }^{\$} p<0.05$ versus L-NAME.
PAI- 1 antigen secreted by both incubated whole and medial aortic ring explants was significantly increased in the L-NAME group as compared to control and L-NAME + ACEI groups (Fig. 5B). A strong correlation $(r=0.85, p<0.0001)$ was observed between PAI-1 levels secreted by aortic and medial ring explants (data not shown). In the L-NAME group, systolic BP and either plasma or secreted PAI- 1 antigen correlated strongly $(r=0.85, p=$ 0.005 and $r=0.72, p<0.05$, respectively; Fig. 5C). In the L-NAME aortas, the amounts of PAI- 1 and t-PA mRNA were significantly increased compared to the control and the L-NAME + ACEI groups (Fig. 5D).

PAI- 1 activity from the arterial wall was visualized as a band of resistance to lysis corresponding to a molecular weight of $\sim 50 \mathrm{kDa}$ (Fig. 6A). This band was significantly increased in the L-NAME group as compared to control and L-NAME + ACEI groups (Fig. 6B).

Fibrinolytic bands in fibrin zymograms were detected in a zone corresponding to the migration of t-PA/PAI-1 complexes (Fig. 6C). Nevertheless, these complexes were not significantly increased in the L-NAME group as compared to the control and the L-NAME + ACEI groups (Fig. 6D).

\section{Discussion}

The present study investigated at a molecular level the relationship between endothelial dysfunctioninduced experimental hypertension and arterial thrombotic risk. Because L-NAME predominantly inhibits endothelial nitric oxide synthase (NOS) activity (23), NO suppression leads to hypertension. This hypertension is probably due to potentiation of intracellular vasoconstrictive signaling secondary to extracellular communications, such as angiotensin II (Ang II), in arterial smooth muscle cells (SMCs) (8). Therefore, inhibition of vasoconstrictive extracellular communications, such as inhibition of the renin-angiotensin system (24), could reverse L-NAME-induced hypertension as do NO donors (5). Beyond this functional vasoconstrictive effect, the excess of intracellular signaling in SMCs, involving oxidative stress and NF- $\kappa \mathrm{B}$ activation, induces a functional remodeling of the arterial wall (9). L-NAME administration at a dose of $50 \mathrm{mg} / \mathrm{kg} /$ day induced severe hypertension concomitant to a large reduction in cyclic GMP, the second messenger of NO in vascular SMCs (5). Because under these experimental conditions deaths begin to occur after 2 months (13), we chose this delay for exploring the hemostasis imbalance involved in the reduction of life expectancy (7). Deaths are related to stroke and nephroangiosclerosis-induced renal insufficiency and are totally prevented by ACE inhibition (7). We therefore explored circulating biomarkers of a procoagulant and antifibrinolytic state and investigated their possible molecular origin in the arterial tissue.

Chronic in vivo activation of platelets in the L-NAME animals may account for their desensitization to in vitro stimulation by ADP or collagen. In vitro, L-NAME potentiates platelet aggregation and platelet recruitment induced by ADP (25), and in vivo L-NAME promotes agonist-induced platelet 

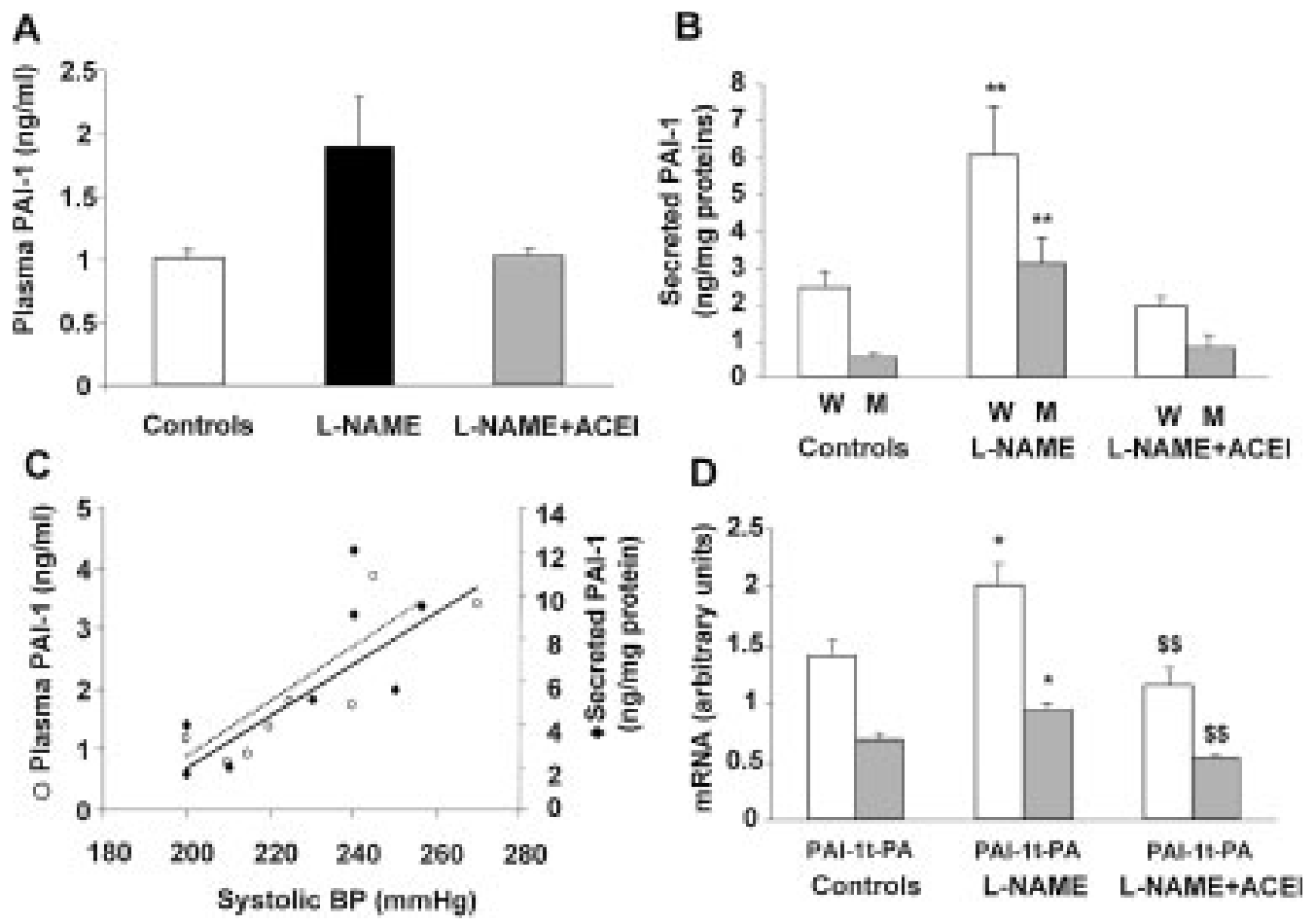

Fig. 5. PAI-1 synthesis and secretion. Evolution of plasma PAI-1 concentration (A) and secreted PAI-1 from tissue explants (B) in the three groups. A significant increase in secreted PAI- 1 in either whole aorta (W) or medial ring (M) was observed in the L-NAME group. Correlations (C) between PAI-1 (plasma $\bigcirc-$ and secreted $\$$. .) and systolic BP in the L-NAME group $(r=0.85, p=0.005$ and $r=0.72, p<0.05$, respectively). The increase in plasma PAI-1 antigen level corresponded to a significant increase in PAI-1 mRNA expression (open bar) in the arterial wall (D). Nevertheless, t-PA mRNA expression (gray bar) was also significantly increased in the arterial wall of the L-NAME rats (D). Values are means \pm SEM. ${ }^{*} p<0.05,{ }^{* *} p<0.01$ versus controls. ${ }^{\$ \$} p<0.005$ versus $\mathrm{L}-\mathrm{NAME}$.

accumulation in the pulmonary vasculature in rabbits (26). We show here that L-NAME administration enhances systemic thrombin production as demonstrated by increased plasma levels of TAT complexes and SGPV, providing evidence of in vivo activation of blood coagulation in a model of hypertensioninduced end-organ damage. The increase in plasma levels of sGPV is a reliable marker of in vivo thrombin-induced platelet activation (17). Therefore, the generation of thrombin probably plays a central role in platelet activation.

TF, the cofactor for factors VII/VIIa, is considered to be the main initiator of the coagulation cascade leading to thrombin generation (15) in tissue and particularly within the vascular wall. In our study, the L-NAME group showed an increase in TF expression at both activity and mRNA levels in large and small arteries correlated to BP. Under normal circumstances, TF activity is constitutively expressed in the adventitia; endothelial and medial cells only weakly express TF. In the present study, TF activity of normal rats was 50-fold higher in the adventitia than in the media layer. In the L-NAME-treated rats, TF mRNA and activity increased significantly in the media as well as in the adventitia layers. These data fit with the recently published overexpression of TF mRNA in the arterial wall in a transgenic model of hypertension in rats (27). In contrast, no activation of TF expression was observed in glomeruli. As compared to the arteriolar wall mainly composed of SMCs and fibroblasts, glomeruli are rich in endothelial cells of capillary origin. Ang II could directly induce TF expression in SMCs (28) via its specific receptor AT-1 and the subsequent activation of the transcription factors NF- $\kappa$ B and AP- 1 , which are implicated in TF gene induction (29). Similarly, chronic administration of L-NAME is associated with $N F-\kappa B$ activation in the arterial wall $(9,30)$. The chronic NO suppression by L-NAME could directly participate in the increase in TF expression because enhanced production of endothelium-derived NO reduces endotoxin- and cytokine-induced expression of TF in vitro (31) and oral administration of L-arginine blunts the increase in monocyte TF response in an experimental model of angioplasty (32).

In vivo, TF-VIIa proteolytic activity is inhibited by TFPI, a circulating multidomain, kunitz-type protease inhibitor (33). Because it has been demonstrated that the imbalance of TF and TFPI causes susceptibility to coagulation disorders (34), we also investigated the expression of glomerular TFPI mRNA and show that it is decreased in L-NAMEtreated rats. By contrast, TFPI mRNA expression in the aorta was not significantly affected by L-NAME administration. This last result is in accordance with Nishimura et al. (35), who demonstrated that Ang II 

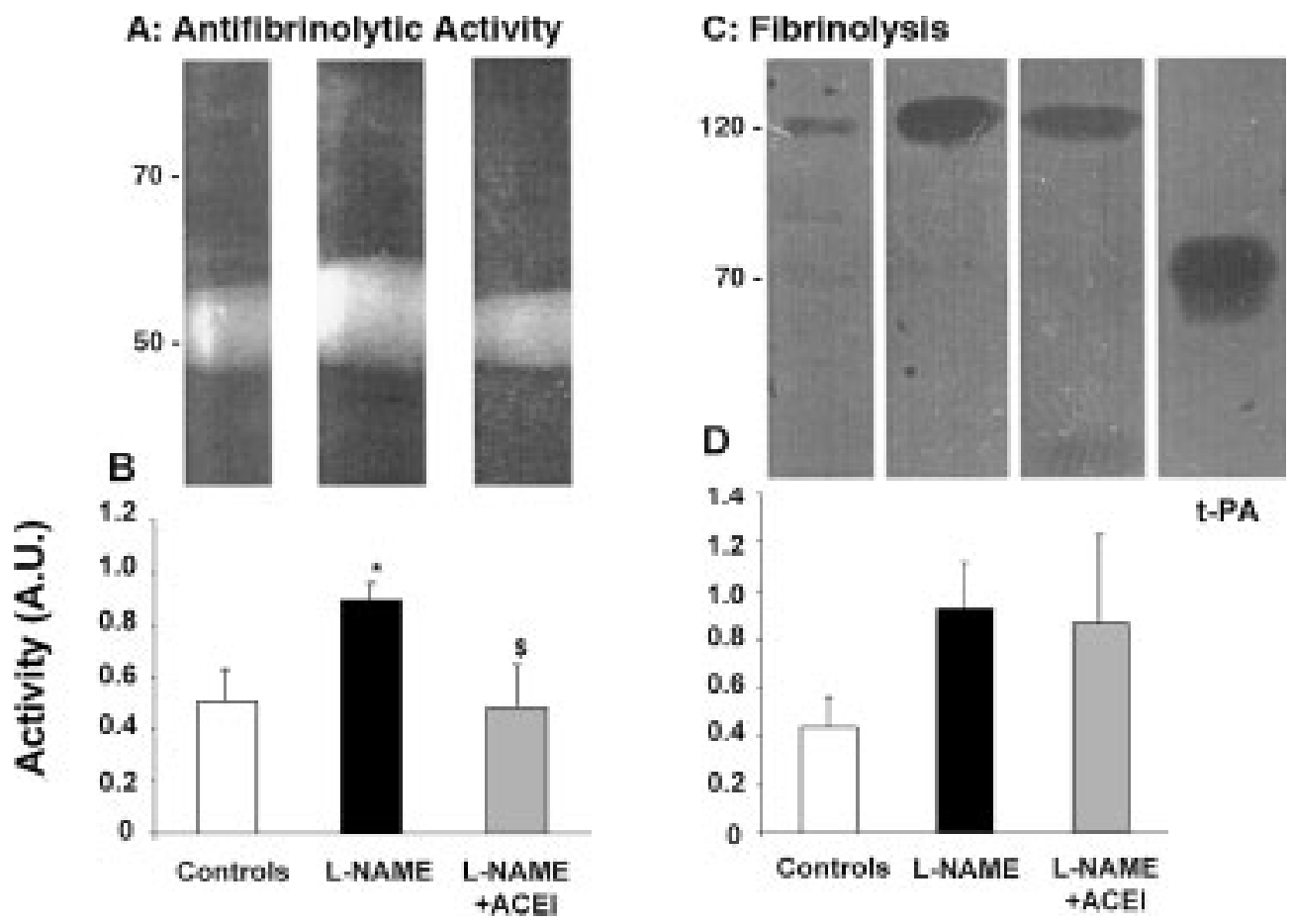

Fig. 6. Fibrinolysis impairment. (A) The antifibrinolytic activity secreted by aortic rings was evaluated by the ability of electrophoresed proteins to inhibit urokinase-dependent plasminogen activation and fibrin degradation. All the antifibrinolytic activity migrated to a molecular weight of $\sim 50 \mathrm{kDa}$ corresponding to PAI-1. (B) The antifibrinolytic activity was significantly higher in the L-NAME group $\left({ }^{*} p<0.05\right.$ versus controls; ${ }^{\$} p<0.05$ versus L-NAME). (C) The fibrinolytic activity secreted by aortic rings was evaluated by the ability of electrophoresed proteins to activate plasminogen and produce plasmin-induced fibrin degradation. All the fibrinolytic activity migrated to a molecular weight of $\sim 120 \mathrm{kDa}$, corresponding to t-PA/PAI-1 complexes. (D) There was no significant difference between the three groups, no free t-PA, and no detectable u-PA. Results are expressed (B,D) in arbitrary units (AU) based on the optical density of gel scan.

increased TF mRNA expression without changing that of TFPI in cultured rat aortic endothelial cells. Moreover, in a recent study, plasma TFPI was not increased in patients with chronic hypertension (36).

Zofenopril totally prevented hypertension, vascular TF overexpression, platelet desensitization, and thrombin generation. Due to its high lipophilic properties, Zofenopril is able to interfere with tissue ACE, preventing Ang II generation at the tissue level and subsequent vascular cell activation (37). Recent studies have showed that Ang II ATlreceptor antagonists can reduce platelet aggregability in the circulation of hypertensive rats (38) and subjects (39), and in human platelet-rich plasma in vitro (40). The reduction of TF procoagulant activity was demonstrated in patients with myocardial infarction treated by an ACE inhibitor (41).

Impaired fibrinolysis could also play an important role in the relationship between the arterial phenotype and the hypercoagulable state associated with hypertension. It has been demonstrated that t-PA, which promotes fibrinolysis, and its inhibitor PAI- 1 are increased in plasma of human hypertensive patients (14). PAI- 1 is considered as an early marker of hypertension (42), and efficient treatment such as ACE inhibition reduces its level $(36,43)$. In vitro, Ang II induced PAI-1 expression by cultured vascular cells (35). Its effect on t-PA expression in cultured vascular cells is less clear (35). In agreement with clinical data, we demonstrate an increase in the plasma PAI-1 antigen level and in PAI-1 mRNA expression and secretion by the arterial wall, and a significant association of these parameters with the systolic BP. Recently, a study also demonstrated the early overexpression of PAI-1 mRNA and immunoreactivity in the aorta of L-NAME rats and its prevention by another ACE inhibitor (10). Nevertheless, despite the increase in PAI-1 plasma antigen and tissue levels, there is no direct demonstration of an antifibrinolytic activity of the arterial wall in animals. Our results show that the arterial wall was largely responsible for the increase in PAI-1. For the first time, beyond the assay of PAI-l antigen, we provide evidence of an antifibrinolytic activity secreted by the arterial wall in experimental hypertension. Conversely, we also show that hypertension is not associated with a profibrinolytic state as demonstrated by the absence of free t-PA activity in the supernatant of arterial wall organoculture.

In conclusion, the present study demonstrates, for the first time, the increase in TF and antifibrinolytic activities and molecules in the arterial and arteriolar wall in an experimental model of hypertension. This is associated with an increase in PAI-1 antigen as 
well as with markers of platelet and coagulation activation in the circulating blood. Nevertheless, this study cannot discriminate between a direct effect of vascular TF or an indirect effect via platelet activation and blood coagulation in the increased risk of ischemic end-organ damage observed in hypertension.

\section{Acknowledgments}

This work was supported by grants from Menarini (Florence, Italy) and by INSERM. D.C. was supported by the Society of Nephrology and V.F. by the French Society of Hypertension. We thank PierreLouis Tharaux and Christos Chatziantoniou for their assistance with the isolation of renal arterioles.

\section{References}

1. Kannel WB. (2000) Elevated systolic blood pressure as a cardiovascular risk factor. Am. J. Cardiol. 85: 251-255.

2. Fuster V, Badimon L, Badimon JJ, Chesebro JH. (1992) The pathogenesis of coronary artery disease and the acute coronary syndromes. N. Engl. J. Med. 326: 242-250.

3. Pessina AC, Serena L, Semplicini A. (1996) Hypertension, coronary artery and cerebrovascular diseases in the population. Has epidemiology changed in the last decades? Clin. Exp. Hypertens. 18: 363-370.

4. Touboul PJ, Elbaz A, Koller C, et al. (2000) Common carotid artery intima-media thickness and brain infarction: the Etude du Profil Genetique de l'infarctus Cerebral (GENIC) case-control study. The GENIC Investigators. Circulation 102: 313-318.

5. Arnal JF, Warin L, Michel JB. (1992) Determinants of aortic cyclic guanosine monophosphate in hypertension induced by chronic inhibition of nitric oxide synthase. J. Clin. Invest. 90: 647-652.

6. Baylis C, Mitruka B, Deng A. (1992) Chronic blockade of nitric oxide synthesis in the rat produces systemic hypertension and glomerular damage. J. Clin. Invest. 90: 278-281.

7. Blot S, Arnal JF, Xu Y, Gray F, Michel JB. (1994) Spinal cord infarcts during long-term inhibition of nitric oxide synthase in rats. Stroke 25: 1666-1673.

8. Henrion D, Dowell FJ, Levy BI, Michel JB. (1996) In vitro alteration of aortic vascular reactivity in chronic L-NAME induced hypertension. Hypertension 28: 361-368.

9. Gonzalez W, Fontaine V, Pueyo ME, et al. (2000) Molecular plasticity of vascular wall during $\mathrm{N}(\mathrm{G})$-nitro-L-arginine methyl ester-induced hypertension: modulation of proinflammatory signals. Hypertension 36: 103-109.

10. Katoh M, Egashira K, Mitsui T, Chishima S, Takeshita A, Narita H. (2000) Angiotensin-converting enzyme inhibitor prevents plasminogen activator inhibitor- 1 expression in a rat model with cardiovascular remodeling induced by chronic inhibition of nitric oxide synthesis. J. Mol. Cell. Cardiol. 32: 73-83.

11. Luvara G, Pueyo M, Philippe M, et al. (1998) Chronic blockade of nitric oxide synthase activity induces pro-inflammatory phenotype in the arterial wall. Prevention by angiotensin II antagonism. Arterioscler. Thromb. Vasc. Res. 18: 1408-1416.

12. Usui M, Egashira K, Kitamoto S, et al. (1999) Pathogenic role of oxidative stress in vascular angiotensin-converting enzyme activation in long-term blockade of nitric oxide synthesis in rats. Hypertension 34: 546-551.

13. Michel JB, Xu Y, Blot S, Philippe M, Chatellier G. (1996) Improved survival in rats administered NG-nitro L-arginine methyl ester due to converting enzyme inhibition. J. Cardiovasc. Pharmacol. 28: 142-148.

14. Tomiyama H, Kimura Y, Mitsuhashi H, et al. (1998) Relationship between endothelial function and fibrinolysis in early hypertension. Hypertension 31: 321-327.
15. Ruf W, Edgington TS. (1994) Structural biology of tissue factor, the initiator of thrombogenesis in vivo. FASEB J. 8: 385390.

16. Mackman N. (1995) Regulation of the tissue factor gene. FASEB J. 9: 883-889.

17. Ravanat C, Freund M, Mangin P, et al. (2000) GPV is a marker of in vivo platelet activation-study in a rat thrombosis model. Thromb. Haemost. 83: 327-333.

18. De Prost D, Le Floch V, Kanfer A. (1985) Quantitative assessment of procoagulant activity in isolated rat glomeruli. Kidney Int. 28: 566-568.

19. Chatziantoniou C, Pauti MD, Pinet F, Promeneur D, Dussaule JC, Ardaillou R. (1996) Regulation of renin release is impaired after nitric oxide inhibition. Kidney Int. 49: 626-633.

20. Battle T, Arnal JF, Challah M, Michel JB. (1994) Selective isolation of rat aortic wall layers and their cell types in culture-application to converting enzyme activity measurement. Tissue Cell 26: 943-955.

21. Caen J, Larrieu MJ, Samama M. (1975) L'expansion Scientifique Française. In L'hémostase. Paris; 313.

22. Gaussem P, Graihle P, Anglés-Cano E. (1993) Sodium dodecyl sulfate-induced dissociation of complexes between human tissue plasminogen activator and its specific inhibitor. J. Biol. Chem. 268: 12150-12155.

23. Darblade B, Batkai S, Caussé E, et al. (2001) Failure of Lnitroarginine to inhibit the activity of aortic inducible nitric oxide synthase. J. Vasc. Res. 38: 266-275.

24. Pollock DM, Polakowski JS, Divish BJ, Opgenorth TJ. (1993) Angiotensin blockade reverses hypertension during longterm nitric oxide synthase inhibition. Hypertension 21: 660-666

25. Freedman JE, Loscalzo J, Barnard MR, Alpert C, Keaney JF, Michelson AD. (1997) Nitric oxide released from activated platelets inhibits platelet recruitment. J. Clin. Invest. 100: 350-356.

26. Emerson M, Momi S, Paul W, Alberti PF, Page C, Gresele P. (1999) Endogenous nitric oxide acts as a natural antithrombotic agent in vivo by inhibiting platelet aggregation in the pulmonary vasculature. Thromb. Haemost. 81: 961-966.

27. Luft FC, Mervaala E, Muller DN, et al. (1999) Hypertensioninduced end-organ damage: a new transgenic approach to an old problem. Hypertension 33: 212-218.

28. Taubman MB, Marmur JD, Rosenfield CL, Guha A, Nichtberger S, Nemerson Y. (1993) Agonist-mediated tissue factor expression in cultured vascular smooth muscle cells. Role of $\mathrm{Ca}^{2+}$ mobilization and protein kinase $\mathrm{C}$ activation. J. Clin. Invest. 91: 547-552.

29. Müller DN, Mervaala EMA, Dechend R, et al. (2000) Angiotensin II $\left(\mathrm{AT}_{1}\right)$ receptor blockade reduces vascular tissue factor in angiotensin II-induced cardiac vasculopathy. Am. J. Pathol. 157: 111-122.

30. Kitamoto S, Egashira K, Kataoka C, et al. (2000) Increased activity of nuclear factor-kappa participates in cardiovascular remodeling induced by chronic inhibition of nitric oxide synthesis in rats. Circulation 102: 806-812.

31. Yang Y, Loscalzo J. (2000) Regulation of tissue factor expression in human microvascular endothelial cells by nitric oxide. Circulation 101: 2144-2148.

32. Corseaux D, Le Tourneau T, Six I, et al. (1998) Enhanced monocyte tissue factor response after experimental balloon angioplasty in hypercholesterolemic rabbit: inhibition with dietary L-arginine. Circulation 98: 1776-1782.

33. Broze GJJ. (1995) Tissue factor pathway inhibitor. Thromb. Haemost. 74: 90-93.

34. Sandset PM, Bonnie J, Warn-Cramer BJ, Rao VM, Maki SL, Rapaport SI. (1991) Depletion of extrinsic pathway inhibitor (EPI) sensitizes rabbits to disseminated intravascular coagulation induced with tissue factor: evidence supporting a physiological role for EPI as a natural anticoagulant. Proc. Natl. Acad. Sci. U.S.A. 88: 708-712.

35. Nishimura H, Tsuji H, Masuda H, et al. (1997) Angiotensin II increases plasminogen activator inhibitor- 1 and tissue factor mRNA expression without changing that of tissue type plasminogen activator or tissue factor pathway inhibitor in 
cultured rat aortic endothelial cells. Thromb. Haemost. 77: 1189-1195.

36. Erdem Y, Usalan C, Haznedaroglu IC, et al. (1999) Effects of angiotensin converting enzyme and angiotensin II receptor inhibition on impaired fibrinolysis in systemic hypertension. Am. J. Hypertens. 12: 1071-1076.

37. Ranadive SA, Chen AX, Serajuddin AT. (1992) Relative lipophilicities and structural-pharmacological considerations of various ACE inhibitors. Pharm. Res. 9: 1480-1486.

38. Li P, Ferrario CM, Brosnihan KB. (1998) Losartan inhibits thromboxane A-2-induced platelet aggregation vascular constriction in spontaneously hypertensive rats. J. Cardiovasc. Pharmacol. 32: 198-205.

39. Levy PJ, Yunis C, Owen J, Brosnihan B, Smith R, Ferrarion CM. (2000) Inhibition of platelet aggregability by losartan in essential hypertension. Am. J. Cardiol. 86: 1188-1192.
40. Li P, Fukuhara M, Diz DI, Ferrario CM, Brosnihan KB. (2000) Novel angiotensin II AT(1) receptor antagonist irbesartan prevents thromboxane $\mathrm{A}(2)$-induced vasoconstriction in canine coronary arteries and human platelet aggregation. J. Pharmacol. Exp. Ther. 292: 238-246.

41. Soejima H, Ogawa H, Yasue H, et al. (1999) Angiotensinconverting enzyme inhibition reduces monocyte chemoattractant protein-1 and tissue factor levels in patients with myocardial infarction. J. Am. Coll. Cardiol. 34: 983-988.

42. Poli KA, Tofler GH, Larson MG, et al. (2000) Association of blood pressure with fibrinolytic potential in the Framingham offspring population. Circulation 101: 264-269.

43. Lottermoser K, Weisser B, Hertfelder HJ, Wostmann B, Vetter H, Dusing R. (1998) Antihypertensive drug treatment and fibrinolytic function. Am. J. Hypertens. 11: 378384 . 